\title{
Proteomics approach to study the mechanism of action of grape seed proanthocyanidin extracts on arterial remodeling in diabetic rats
}

\author{
XIAO-LI LI ${ }^{1,2^{*}}$, BAO-YING LI ${ }^{1 *}$, HAI-QING GAO ${ }^{1}$, MEI CHENG ${ }^{1}$, \\ LING XU ${ }^{1}$, XIAN-HUA LI ${ }^{1}$, WEI-DONG ZHANG ${ }^{3}$ and JIAN-WEN HU ${ }^{4}$

\begin{abstract}
Departments of ${ }^{1}$ Geriatrics and ${ }^{2}$ Drug Purchase and Supply, Qi-Lu Hospital of Shandong University; ${ }^{3}$ Department of Pathology, Institute of Basic Science, Medical Science Academy of Shandong, Jinan; ${ }^{4}$ Research Center for Proteome Analysis, Shanghai Institute for Biological Sciences, Chinese Academy of Sciences, Shanghai, P.R. China
\end{abstract}

Received July 17, 2009; Accepted August 27, 2009

DOI: 10.3892/ijmm_00000336

\begin{abstract}
Arterial remodeling is the change in structural properties of vessel in diabetes mellitus and contributes to the development of vascular complications. To prevent this development and to improve diabetic vascular complications, effective therapies directed toward the key molecular target are required. Grape seed proanthocyanidin extracts (GSPE) have been reported to be effective in treating arteriosclerosis, while little is known about the functional protein changes. We used streptozocin to induce diabetic rats. GSPE (250 $\mathrm{mg} / \mathrm{kg}$ body weight/day) were administrated to diabetic rats for 24 weeks. Consequently, 2-D difference gel electrophoresis and mass spectrometry were used to investigate aortic protein profiles among the control, untreated and GSPEtreated diabetic rats. The expression of 23 proteins was found either up-regulated or down-regulated in the aorta of untreated diabetic rats. Only the expression of 15 proteins was found either down-regulated or up-regulated in the aorta of GSPEtreated diabetic rats. Our findings might help to better understand the mechanism of diabetic macrovascular complications and provide novel targets for evaluating the effects of GSPE therapy.
\end{abstract}

\section{Introduction}

Vascular complications are the leading cause of mortality in diabetic patients. The mechanisms responsible for this increased risk remain unclear, but are likely to involve functional and structural alterations in large arteries $(1,2)$.

Correspondence to: Dr Hai-qing Gao, Department of Geriatrics, Qi-Lu Hospital of Shandong University, 107 Wenhuaxi Road, Jinan, Shandong Province 250012, P.R. China

E-mail: gaohaiqing52@hotmail.com

*Contributed equally

Key words: grape seed proanthocyanidin extracts, diabetes mellitus, arterial remodeling, proteomics, heat shock protein 27
Arterial remodeling is characterized by wall thickening and diameter widening. At the biochemical level, the key molecular targets of arterial remodeling are not completely understood in diabetes mellitus (DM). Therefore, it is important to identify the expression of key protein in diabetic arterial remodeling so that the effectiveness of early intervention can be assessed.

Grape seed proanthocyanidin extracts (GSPE) derived from grape seeds, have been reported to possess a variety of potent properties including anti-oxidant, anti-inflammation and anti-tumor $(3,4)$. It was reported that GSPE had an antiathero-sclerotic effect in protecting the aortic wall of cholesterol-fed rabbits (5). Our previous experiments showed that GSPE displayed anti-non-enzymatic glycation and antiinflammation, subsequently leading to decreased expression of high level vascular cell adhesion molecule 1 induced by advanced glycation end products (AGEs) in endothelial cells $(6,7)$.

The pathogenetic mechanism of arterial remodeling caused by DM is unclear and there is no cure for diabetes so far. For this reason, further comparative analyses of protein expression profiles in aorta of diabetic rats are needed. We took streptozocin (STZ)-induced diabetic rats as an animal model, collected aorta of the control, untreated, and GSPEtreated diabetic rats, and applied them to 2-D difference gel electrophoresis (2-D DIGE), followed by analysis using AutoFlex martix-assisted laser desorption/ionization time-offlight mass spectrometry with LIFT technology (MALDI-TOF/ TOF MS) or liquid chromatography electrospray ionisation mass spectrometry/mass spectrometry (LTQ-ESI-MS/MS). In our present study, we verified the different expression of some proteins in diabetic rats, among which some were either down-regulated or up-regulated after treatment with GSPE.

\section{Materials and methods}

Materials. GSPE (56\% dimeric proanthocyanidins, $12 \%$ trimeric proanthocyanidins, $6.6 \%$ tetrameric proanthocyanidins and small amounts of monomeric and high-molecular-weight oligomeric proanthocyanidins, and flavanols. Lot No: G050412) were provided by Jianfeng Inc (Tianjin, China). STZ was obtained from Sigma-Aldrich Corp (St. Louis, MO, USA). 
Cy2, Cy3, Cy5, IPG strips, and IPG buffer were from GE Healthcare (Little Chalfont, Bucks, UK). Mouse monoclonal antibody to proliferating cell nuclear antigen (PCNA) and rabbit polyclonal IgG antibody to heat shock protein 27 (HSP27) were provided by Abcam (UK). Fluorescein-conjugated goat anti-mouse secondary antibody was provided by Santa Cruz Biotechnology, Inc (USA). TdT in situ apoptosis detection kit was provided by R\&D Systems, Inc (USA). All other reagents used were standard commercial high-purity materials.

Animals. Male Wistar rats $(\mathrm{n}=60,10$-weeks-old) were purchased from Laboratory Animal Center of Shandong University (Shandong, China). The animals were housed in cages and received normal rat chow and tapwater ad libitum in a constant environment (room temperature $22 \pm 1.5^{\circ} \mathrm{C}$, room humidity $55 \pm 5 \%$ ) with a 12 -h light, 12 -h dark cycle. The animals were kept under observation for one week prior to the start of the experiments. All procedures were approved by the Animal Ethics Committee of Shandong University. Fifteen rats were randomly selected as control group (vehicle, $\mathrm{C}, \mathrm{n}=12$ ), which received a single tail vein injection of $0.1 \mathrm{~mol} / \mathrm{l}$ citrate buffer only. The other 48 rats received a single dose of STZ (55 mg/kg, injected into tail veins) freshly dissolved in $0.1 \mathrm{~mol} / \mathrm{l}$ sodium citrate buffer $(\mathrm{pH} 4.5)$ after a $12 \mathrm{~h}$ overnight fasting (8). Only rats with blood glucose $>16.7 \mathrm{mmol} / \mathrm{l}$ after five days were considered as being diabetic in the fasting state, by using a One Touch II Glucose Analyzer (Johnson \& Johnson, USA). Eight rats with blood glucose levels of $<16.7 \mathrm{mmol} / \mathrm{l}$ were excluded from the study. All studies were carried out one week after STZ had been injected. The diabetic rats were divided into 2 groups: an untreated diabetic group (DM, n=20) and another diabetic group treated by GSPE with a dosage of $250 \mathrm{mg} / \mathrm{kg}$ (DMT, n=20). GSPE was given in normal saline solution by intragastric administration for 24 weeks. Each group of rats was observed from week 1 to weeks 24 without any administration of hypoglycemic therapy. At the end of the intervention, all rats were fasted overnight and then sacrificed. Fasting blood was collected and the aortas were dissected. Aortic tissues and sera were kept at $-80^{\circ} \mathrm{C}$ until further analysis.

Estimation of body weight, fasting blood blucose (FBG),

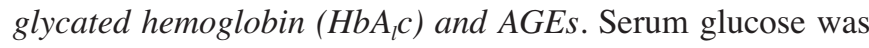
estimated with a commercially available kit (Adamco Ltd., USA). Serum $\mathrm{HbA}_{1} \mathrm{c}$ level was determined using highperformance liquid chromatography (DCA2000, Bayer, Germany). Serum AGEs-specific fluorescence determinations were performed by measuring emission at $440 \mathrm{~nm}$ on excitation at $370 \mathrm{~nm}$ using a fluorescence spectrophotometer (Hitachi 850, Japan).

Light microscopy, immunofluorescence staining and terminal deoxynucleotidyl transferase-mediated dUTP nick endlabeling (TUNEL) assay. A 1-cm sample of the descending thoracic aorta was excised and fixed in $10 \%$ formaldehyde and embedded in paraffin and cut into $4 \mu \mathrm{m}$-thick sections for light microscopy. Then they were stained with hematoxylineosin under a light microscope at a magnification of x200 and $\mathrm{x} 400$. The numbers of vascular smooth muscle cells (VSMC) were counted by light microscopy in 5 randomly selected high power fields (x400) in each section. For assessment of proliferation in the VSMC, cross sections were stained by immunofluorescence using an antibody directed against PCNA (9). In brief, sections were incubated with a monoclonal antiPCNA antibody (1:100 dilution), followed by incubation with a fluorescein-conjugated goat anti-mouse secondary antibody (1:200 dilution). Images were captured following confocalmicroscopy. The number of fluorescence labelled PCNApositive nuclei within each layer was counted and a PCNA labelling index was calculated $100 \%$ (number of PCNApositive nuclei/total number of nuclei). Moreover, apoptosis was detected in situ on thoracic aorta cross sections by TUNEL essentially as previously described $(9,10)$. The sections were permeabilized with $20 \mu \mathrm{g} / \mathrm{ml}$ of proteinase $\mathrm{K}$ for $30 \mathrm{~min}$ after which dUTP and TdT enzyme were added according to the manufacturer's specifications. VSMC with a brown-red nuclear labelling were defined as TUNEL-positive and a TUNEL index was calculated $100 \%$ (number of TUNEL-positive nuclei/ total number of nuclei).

Protein sample preparation. To perform a differential proteome analysis, aortas from control group $(\mathrm{C}, \mathrm{n}=3)$, untreated diabetic group (DM, $n=3)$ and diabetic group treated by GSPE with a dosage of $250 \mathrm{mg} / \mathrm{kg}$ (DMT, $\mathrm{n}=3$ ) were dissected from the brachiocephalic trunk to the iliac bifurcation and rinsed thoroughly with ice-cold phosphatebuffered saline to remove any blood components and blotted dry and frozen immediately in liquid nitrogen. Every aortic tissue was cut into small pieces and pulverized under liquid nitrogen into a fine powder. Afterward the resulting powder was ground in a Dounce homogenizer for $20 \mathrm{~min}$ on ice in $1 \mathrm{ml}$ DIGE lysis buffer containing: $7 \mathrm{~mol} / \mathrm{l}$ urea, $2 \mathrm{~mol} / \mathrm{l}$ thiourea, $4 \%$ CHAPS, $0.2 \%$ carrier ampholyte, $\mathrm{pH} 3-10 \mathrm{NL}$ (IPG buffer) and a complete proteinase inhibitor cocktail. For improved cell lysis, the solution was sonicated on ice for $1 \mathrm{~min}$ with $1 \mathrm{sec}$ pulse-on and $1 \mathrm{sec}$ pulse-off to prevent overheating. The suspension was sonicated for $30 \mathrm{sec}$ followed by centrifugation at 25,000 $\mathrm{xg}$ for $1 \mathrm{~h}$. The supernatant was aliquoted and stored at $-80^{\circ} \mathrm{C}$. Protein concentration was determined with the Bradford assay kit (Bio-Rad) using albumin diluted in lysis buffer as standard.

Protein labeling with CyDye DIGE fluor. Aortic tissue lysates were labeled with $\mathrm{Cy} 2, \mathrm{Cy} 3$ and $\mathrm{Cy} 5$ following the protocols described in the Ettan DIGE User Manual (GE Healthcare). Typically, $50 \mu \mathrm{g}$ of lysates ( $\mathrm{pH} 8.5$ ) was labeled with $400 \mathrm{pmol}$ of $\mathrm{Cy} 3$ or $\mathrm{Cy} 5$, while the same amount of the internal standard that contained equal quantities of all the samples was labeled with Cy2. Labeling reactions were carried out in the dark on ice for $30 \mathrm{~min}$ before quenching with $1 \mu \mathrm{l}$ of $10 \mathrm{mM}$ lysine for $10 \mathrm{~min}$ on ice. These labeled samples were then combined for 2-D DIGE analysis.

Two-dimensional gel electrophoresis. Two-dimensional electrophoresis (2-DE) was performed as previously described (11). 2-DE was performed. IPG strips $(13 \mathrm{~cm}$, $\mathrm{pH}$ 3-10 and NL) were rehydrated with labeled samples in the dark, overnight with rehydrated buffer $(8 \mathrm{M}$ urea, $4 \% \mathrm{w} / \mathrm{v}$ CHAPS, $20 \mathrm{mM}$ DTT and 1\% v/v IPG buffer and trace amount 
of bromophenol blue). First-dimension IEF was performed using an Ettan IPGphor System (GE Healthcare) for a total of $60 \mathrm{kVh} 20^{\circ} \mathrm{C}$. The strips were then treated with a two-step reduction and alkylation step prior to the second dimension (SDS-PAGE). After equilibration with a solution containing $6 \mathrm{M}$ urea, $30 \%$ glycerol, $2 \% \mathrm{SDS}, 50 \mathrm{mM}$ of Tris-Cl, $\mathrm{pH} 8.8$ and $0.5 \% \mathrm{w} / \mathrm{v}$ DTT, the strips were treated with the same solution containing $4.5 \% \mathrm{w} / \mathrm{v}$ iodoacetamide instead of DTT. The strips were overlayered onto $12.5 \%$ polyacrylamide gels $(16 \times 16 \mathrm{~cm})$, immobilized to a low-fluorescent glass plate and electrophoresed for $5 \mathrm{~h}$ at $30 \mathrm{~mA}$ per gel using a Hofer SE 600 Series standard dual-cooled gel electrophoresis unit (GE Healthcare). The Cy2, Cy3 and Cy5-labeled images were acquired on a Typhoon 9400 scanner (GE Healthcare) at the excitation/emission values of 488/520, 532/580, 633/670 nm, respectively.

Image analysis. DIGE images were analyzed with DeCyder software (GE Healthcare) as described in the Ettan DIGE user manual. We defined $\mathrm{P}<0.05$ as significant difference when analyzing the parallel spots between groups with Student's t-test. Protein spots were chosen for picking and identification at $\mathrm{P}<0.01$, provided that they were also detected in 15 out of 15 spot maps (i.e. 5 out of 5 gels) and were up- or downregulated by more than \pm 1.25 -fold $(12,13)$.

In-gel trypsin digestion. Three separate preparative gels were run to obtain sufficient amounts of protein for MS analysis. These gels were fixed and stained with colloidal Coomassie brilliant blue (CBB). Proteins of interest, as defined by the 2-D DIGE/DeCyder analysis, were excised from the cCBBstained gels for a modified in-gel trypsin digestion procedure (11). The peptides mixture was solubilized with $1 \%$ TFA for mass spectrometry analysis.

\section{$M S$ and protein identification}

MALDI-TOF/TOF MS analysis and the database search. Mass spectra were acquired on an AutoFlex MALDI-TOF/TOF mass spectrometer with LIFT technology (Bruker Daltonics, Bremen, Germany). The acceleration voltage was set at $20 \mathrm{kV}$ and the cut-off mass value was set at 500. For acquisition of a mass spectrometric peptide map, a $1 \mu 1$ aliquot from the peptide extracts was premixed with $1 \mu 1$ of matrix $(7 \mathrm{mg} / \mathrm{ml}$ CHCA in $30 \%$ ACN and $0.1 \%$ TFA) and spotted onto a MALDI target plate. Measurements were externally calibrated with a standard peptide mixture of angiotensin I [ $(\mathrm{M}+\mathrm{H})+$ $1296.6853 \mathrm{Da}]$ and angiotensin II $([\mathrm{M}+\mathrm{H}]+1046.5420 \mathrm{Da})$ and internally recalibrated with peptide fragments arising from autoproteolysis of trypsin. Both MS and MS/MS data were acquired with an N2 laser at a 25-HZ sampling rate. Mass peaks with the signal to noise ratio of 20 and above was used for the database search. For MS/MS spectra, the peaks were calibrated by default and smoothed. All peaks were deisotoped.

The FlexAnalysis 2.4 software suite was used to generate the peak lists of all acquired MS/MS spectra. MS/MS was performed using the MASCOT search employing BioTools 3.0 software (Bruker Daltonics). The data were sent to the National Center for Biotechnology non-redundant (NCBInr) protein database (NCBInr 20070518; 4927571 sequences, 1702359384 residues). The search was performed taking
Rattus as taxonomy, which contained 40233 sequences. The other search parameters were enzyme of specificity strict trypsin; one missed cleavage; fixed modifications of carbamidomethyl (C); oxidation (Met); peptide mass tolerance of $\pm 100 \mathrm{ppm}$; fragment mass tolerance of $\pm 0.8 \mathrm{Da}$; peptide charge of 1+; and monoisotopic. Proteins matching more than two peptides and with a MASCOT score $>75$ were considered significant $(\mathrm{P}<0.05)(14,15)$.

LTQ-ESI-MS/MS analysis and the database search. Unidentified peptide mixtures by MALDI-TOF/TOF MS/MS were measured using on an LTQ-ESI-MS/MS (Thermo Finnigan, San Jose, CA, USA), using a surveyor high performance liquid chromatography (HPLC) system. The system was fitted with a C18 RP column $(0.15 \times 150 \mathrm{~mm}$, Thermo Hypersil-Keystone). Mobile phase A $(0.1 \%$ formic acid in water) and the mobile phase B $(0.1 \%$ formic acid in ACN) were selected. The tryptic peptide mixtures were eluted using a gradient of $2-98 \% \mathrm{~B}$ over $60 \mathrm{~min}$. The temperature of the heated capillary was set at $170^{\circ} \mathrm{C}$. A voltage of $3.0 \mathrm{kV}$ applied to the ESI needle resulted in a distinct signal. The normalized collision energy was 35.0. The number of ions stored in the ion trap was regulated by the automatic gain control. Voltages across the capillary and the quadrupole lenses were tuned by an automated procedure to maximize the signal for the ion of interest. The LTQ mass spectrometer was set so that one full MS scan was followed by $10 \mathrm{MS} / \mathrm{MS}$ scans on the ten most intense ions from the MS spectrum. Dynamic Exclusion was set at repeat count 2; repeat duration $30 \mathrm{sec}$, exclusion duration $90 \mathrm{sec}$.

For protein identification and statistical validation, the acquired MS/MS spectra were automatically searched against the Internation Protein Index (IPI) RAT version 3.15.1 database using the Turbo SEQUEST program in the BioWorks ${ }^{\mathrm{TM}} 3.1$ software suite. An accepted SEQUEST result had to have a DelCN score of at least 0.1 (regardless of charge state). Peptides with a +1 charge state were accepted if they were fully tryptic and had a cross correlation (Xcorr) of at least 1.9. Peptides with a +2 charge state were accepted if they had an $X$ corr $\geq 2$.2. Peptides with a +3 charge state were accepted if they had an Xcorr $\geq 3.75$. Identifications were validated when considering at least two peptide sequences per protein. To sort out a single protein member from a protein group, we chose the protein with the highest sequence coverage.

Quantitative real-time PCR, immunohistochemistry and Western blot analysis of heat shock protein 27 (HSP27). Total RNA was extracted from aortic tissue of 3 groups of the rats and underwent quantitative analysis of mRNA expression of HSP27 by use of real-time PCR with an ABI Prism 7500 sequence detection system (Applied Biosystems, UK) in 96-well plates. The reaction reagent SYBR-Green I master mix kit (Stratagene) was used according to the manufacturer's instructions. To synthetize the first-strand cDNA, RT was performed using $1 \mu \mathrm{g}$ of total RNA in a $20 \mu \mathrm{l}$ final volume of reaction mixture (10X reaction buffers, $10 \mathrm{mM}$ dNTP mix, Ribonuclease inhibitor, Oligo dT and AMV reverse transcriptase) by incubation at $42^{\circ} \mathrm{C}$ for $30 \mathrm{~min}$ and $95^{\circ} \mathrm{C}$ for $5 \mathrm{~min}$. The reaction was stopped by incubation at $5^{\circ} \mathrm{C}$ for $5 \mathrm{~min}$ (RT kit from MBI, Canada). The reaction components consisted of $10 \mu 1$ of $2 x$ SYBR-Green I master mix, $1 \mu 1$ up-stream primers 
Table I. Effect of GSPE on body weight, $\mathrm{FBG}, \mathrm{HbA}_{1} \mathrm{c}$, AGEs of diabetic rats.

\begin{tabular}{lccc}
\hline Parameters & $\mathrm{C}(\mathrm{n}=10)$ & $\mathrm{DM}(\mathrm{n}=9)$ & DMT $(\mathrm{n}=13)$ \\
\hline Body weight, g & $523.56 \pm 46.87$ & $193.20 \pm 36.65^{\mathrm{b}}$ & $327.48 \pm 57.90^{\mathrm{b}, \mathrm{d}}$ \\
FBG, mmol/l & $6.99 \pm 2.74$ & $23.03 \pm 3.38^{\mathrm{b}}$ & $21.23 \pm 3.92^{\mathrm{b}}$ \\
$\mathrm{HbA}_{1} \mathrm{c}, \%$ & $5.61 \pm 0.73$ & $12.40 \pm 2.35^{\mathrm{b}}$ & $11.41 \pm 2.14^{\mathrm{b}}$ \\
AGEs, AU/mg & $0.017 \pm 0.004$ & $0.035 \pm 0.012^{\mathrm{b}}$ & $0.023 \pm 0.008^{\mathrm{a}, \mathrm{c}}$
\end{tabular}

${ }^{\mathrm{a} P}<0.05,{ }^{\mathrm{b}} \mathrm{P}<0.01$ : vs. $\mathrm{C}$; ${ }^{\mathrm{C}} \mathrm{P}<0.05,{ }^{\mathrm{d}} \mathrm{P}<0.01$ : DMT vs. DM. C, untreated control group; DM, untreated diabetic group; DMT, GSPE-treated diabetic group. FBG, fasting blood glucose; $\mathrm{HbA}_{1} \mathrm{c}$, glycated hemoglobin; AGEs, advanced glycation end products.

(10 $\mu \mathrm{mol} / \mathrm{l}), 1 \mu \mathrm{l}$ down-stream primers $(10 \mu \mathrm{mol} / \mathrm{l}), 1 \mu \mathrm{l} \mathrm{cDNA}$ and $7 \mu 1$ double distilled water. Sequences of the primer sets used were as follows: HSP27 (forward) 5'-GCAGGATGAA CATGGCTACATCTC-3', (reverse) 5'-TGGTGATCTCCG CTGATTGTG-3'; ß-actin (forward) 5'-GGAGATTACTGC CCTGGCTCCTA-3', (reverse) 5'-GACTCATCGTACTCC TGCTTGCTG-3'. The PCR conditions for all genes were as follows: $50^{\circ} \mathrm{C}$ for $2 \mathrm{~min}$; preheating, $95^{\circ} \mathrm{C}$ for $10 \mathrm{~min}$; followed by 40 cycles of denaturation $\left(95^{\circ} \mathrm{C}\right.$ for $\left.15 \mathrm{sec}\right)$ and annealing/ elongation $\left(60^{\circ} \mathrm{C}\right.$ for $\left.1 \mathrm{~min}\right)$. Each sample was run in triplicate. Gene-specific mRNA was normalized to ß-actin mRNA as an internal control. The amounts of HSP27 mRNA in aorta of group DM and DMT were expressed as fold change relative to those of group $\mathrm{C}$ set as 1 .

Immunohistochemistry was performed on the paraffinembedded tissue sections using a standard avidin-biotin complex-peroxidase method using 3, 3'-diaminobenzidine as chromogen. Briefly, sections were deparaffinized with xylene and serial gradient concentration of alcohol was used to dehydrate. Endogenous peroxidase was blocked by incubation with $3 \%$ hydrogen peroxide for $5 \mathrm{~min}$. After washing with phosphate-buffered saline, the sections were incubated in $10 \%$ sheep serum for $5 \mathrm{~min}$, followed by overnight incubation with rabbit anti-rat polyclonal antibodies against HSP27 (1:250). Sections were then incubated with biotinylated anti-rabbit IgG followed by an avidin-biotin peroxidase complex. Normal rabbit $\operatorname{IgG}$ of the same concentrations was used to substitute for the rabbit polyclonal antibodies as negative control. Immunohistochemical-stained aorta slides were analyzed by an observer blinded to the aorta conditions. Brown areas were judged as positive based on the manufacturing information from Image Leica Qwin v3 software (Leica DM 4000B, Germany), which was used to measure the grey value of immunochemistry within each aorta region.

Western blot analysis was performed on samples of aortic tissue obtained from 3 groups of the rats. Equal amount of proteins were separated by electrophoresis in a $12 \%$ SDSpolyacrylamide gel. After the proteins were transferred onto a polyvinylidene difluoride membrane (Millipore, Bedford, MA, USA), the blot was blocked with $5 \%$ (w/v) non-fat milk in TBST (Tris-buffered saline and $0.05 \%$ Tween-20) for $1 \mathrm{~h}$ at room temperature and then probed with anti-HSP27 (1:1000) polyclonal antibody and anti- $\beta$-actin (1:500), followed by incubation with secondary antibody, horseradish peroxidaseconjugated affinity anti-rabbit $\operatorname{IgG}(1: 7500)$ for $1 \mathrm{~h}$. Signal detection was performed via exposing the blots to enhanced
DAB color reagent for 5 min. Quantification of the luminosity of each identified protein band was performed using a densitometric analysis (Digital Protein DNA Imagineware, Huntington Station, NY, USA).

Statistical analysis. Data are expressed as mean \pm standard deviation. Statistical significance of the differences among experimental groups was calculated by unpaired Student's t-test and one way ANOVA. P-value $<0.05$ was considered statistically significant.

\section{Results}

Effects of GSPE on body weight, FBG, $\mathrm{Hb} A_{l} c$ and AGEs. Table I shows the results of comparisons of body weight, $\mathrm{FBG}, \mathrm{HbA}_{1} \mathrm{c}$ and AGEs findings among the control, untreated and GSPE-treated diabetic rats. The body weight of diabetic rats was significantly smaller than that of control rats at 24 weeks $(\mathrm{P}<0.01)$. GSPE improved the body weight of diabetic rats at 24 weeks $(\mathrm{P}<0.01)$. The $\mathrm{FBG}, \mathrm{HbA}_{1} \mathrm{c}$ and $\mathrm{AGEs}$ of diabetic rats were higher than those of the control rats $(\mathrm{P}<0.01)$. GSPE significantly reduced the AGEs of diabetic rats $(\mathrm{P}<0.05)$, but GSPE could not decrease the FBG and $\mathrm{HbA}_{1} \mathrm{c}$ of diabetic rats.

Histological findings. In the diabetic rats, aortic remodeling and proliferation of VSMC were observed in the thoracic aorta and the nuclei were impaired and the degeneration was exacerbated in the aortic tissue. Moreover, in the diabetic rats, GSPE suppressed the aortic remodeling and proliferation of VSMC and led to light microscopic findings similar to those of the control rats (Figs. 1 and 2). In the diabetic rats, the PCNA labelling index and number of VSMC were significantly higher than that of control rats $(\mathrm{P}<0.01)$. GSPE significantly reduced the PCNA labelling index and number of VSMC of diabetic rats $(\mathrm{P}<0.01)$. GSPE increased TUNEL index of of diabetic rats VSMC $(\mathrm{P}<0.01)$. The apoptosis and TUNEL index of VSMC was not significantly different among the control and untreated diabetic rats $(\mathrm{P}>0.05)$ (Fig. 3).

DIGE and mass spectrometry. 2-D DIGE was used to generate the protein expression profiles of 9 aortic samples of C, DM and DMT (Fig. 4). Spots detected by cCBB staining were excised and used for identification. In total, up to 1279-1563 different spots were detected on the 5 gels as determined by 

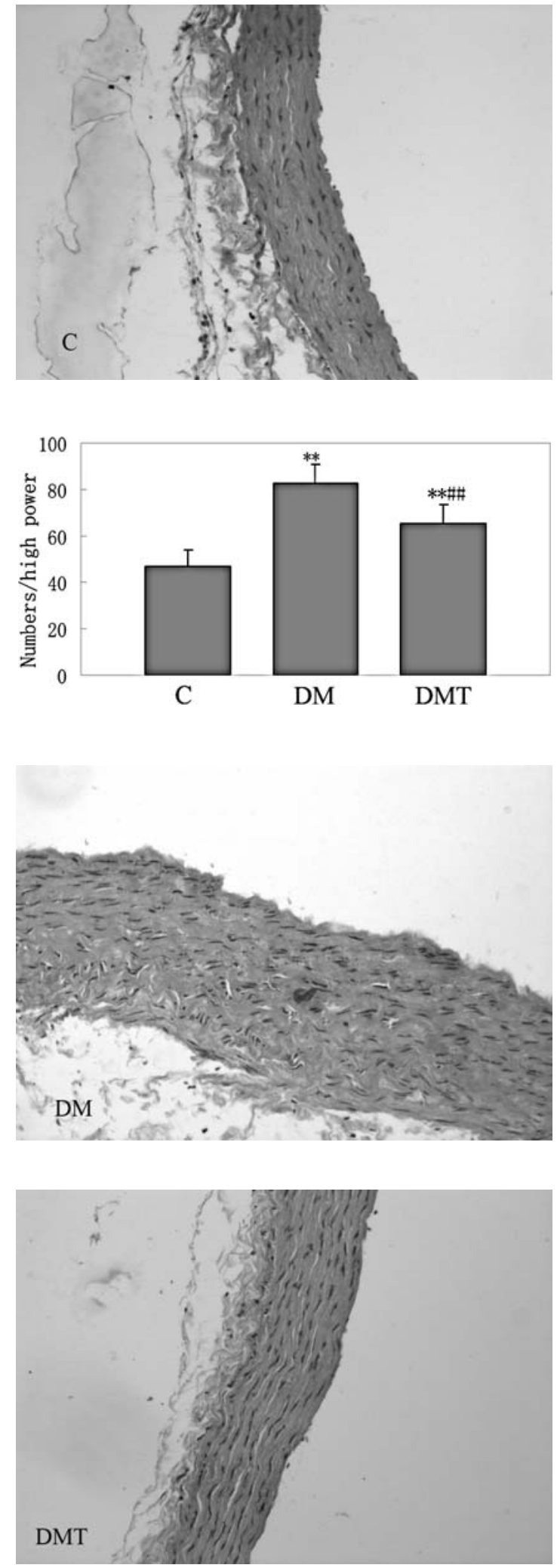

Figure 1. Representative light micrographs of the thoracic aorta (hematoxylineosin; $\mathrm{x} 200)$. The numbers of VSMC in high power $(\mathrm{x} 400) .{ }^{*} \mathrm{P}<0.05,{ }^{* * *} \mathrm{P}<0.01$ compared with $\mathrm{C} ;{ }^{\#} \mathrm{P}<0.05,{ }^{\# \#} \mathrm{P}<0.01$ compared with DM. C, untreated control group; DM, untreated diabetic group; DMT, GSPE-treated diabetic group.

the DeCyder Differntial Analysis Software. Intergel matching was performed through the inclusion of the internal standard on each gel. AutoFlex MALDI-TOF/TOF mass spectrometer with LIFT technology was first used to analyze the peptides
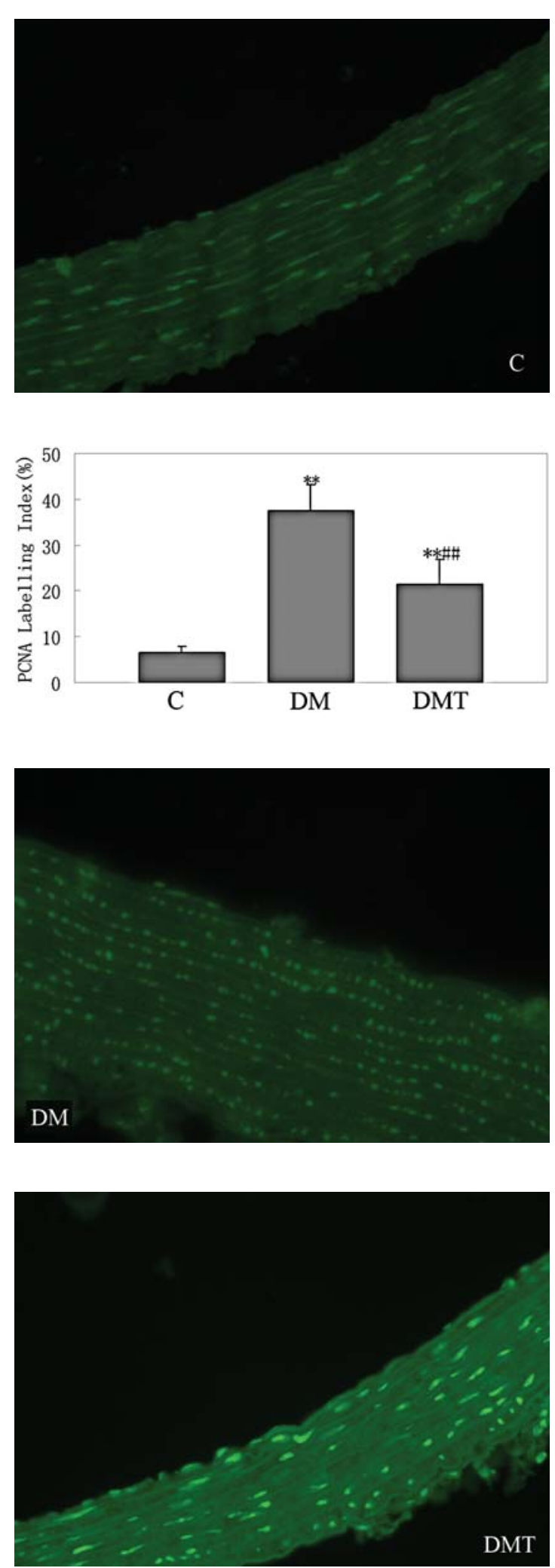

Figure 2. Effects of GSPE on the expression of PCNA of the thoracic aorta (immunofluorescence; $x 400$ ). Percentage of PCNA-positive VSMC in the thoracic aorta. ${ }^{*} \mathrm{P}<0.05,{ }^{* *} \mathrm{P}<0.01$ compared with $\mathrm{C}$; ${ }^{*} \mathrm{P}<0.05,{ }^{\# \#} \mathrm{P}<0.01$ compared with DM. C, Untreated control group; DM, untreated diabetic group; DMT, GSPE-treated diabetic group.

after in-gel digestion of each spot. The spots which could not be identified with MALDI-TOF/TOF MS/MS were then analyzed by LTQ-ESI-MS/MS. Four protein spots were 

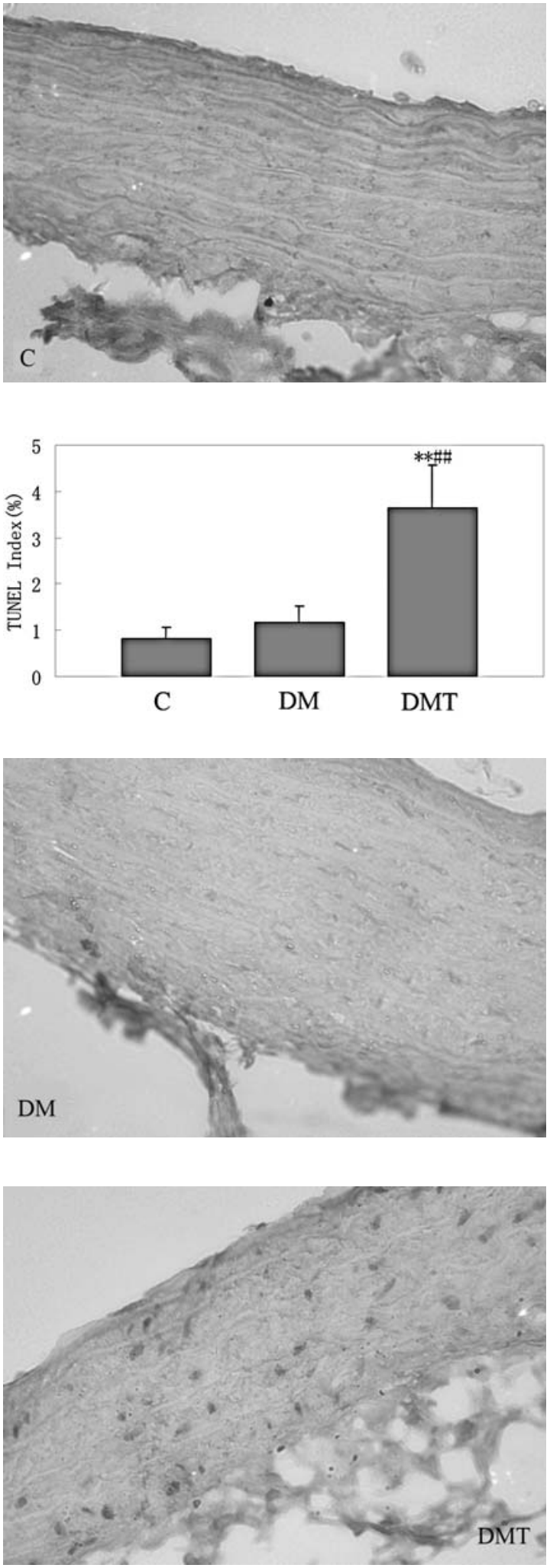

Figure 3. Effects of GSPE on VSMC apoptosis of the thoracic aorta (x400). Percentage of TUNEL-positive VSMC in the thoracic aorta. ${ }^{*} \mathrm{P}<0.05$, ${ }^{* *} \mathrm{P}<0.01$ compared with $\mathrm{C}$; ${ }^{*} \mathrm{P}<0.05,{ }^{\# \#} \mathrm{P}<0.01$ compared with $\mathrm{DM}$. C, untreated control group; DM, untreated diabetic group; DMT, GSPE-treated diabetic group.

successfully identified by MALDI-TOF/TOF MS/MS, including standard spot (SSP) number on 2-DE DIGE gels, NCBI accession number, protein description, theoretical $\mathrm{Mr} / \mathrm{PI}$, sequence coverage and sequence (Table II). Nineteen

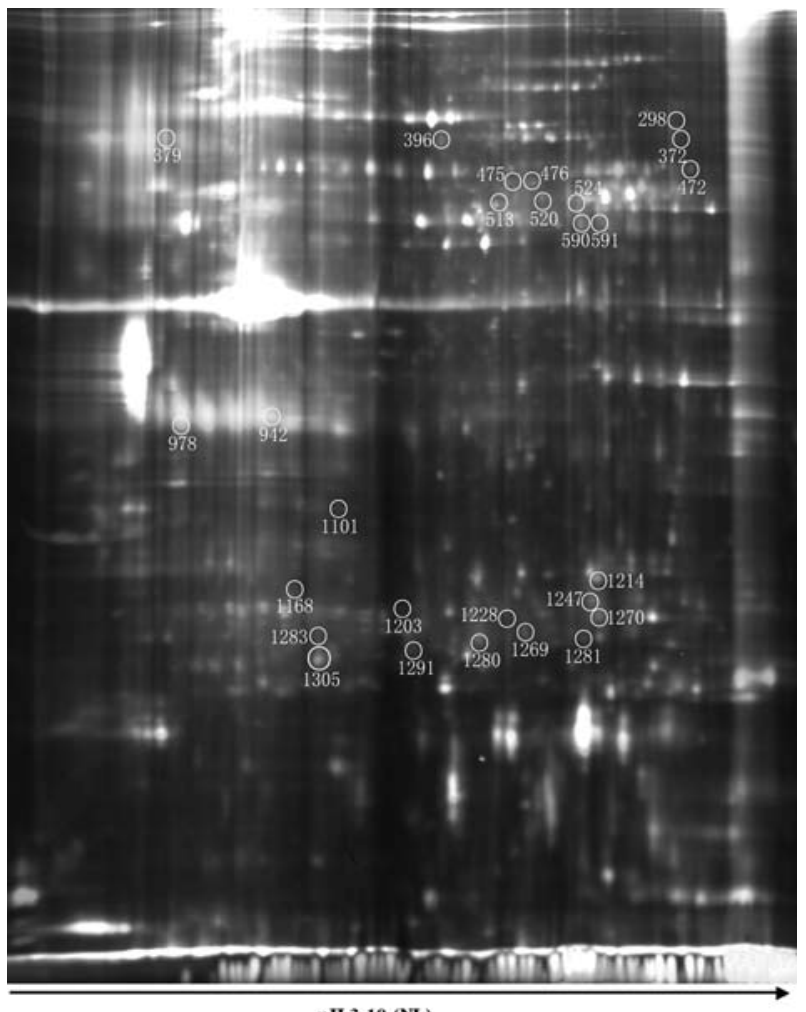

pH 3-10 (NL)

Figure 4. Representative 2-D DIGE images of aorta lysates from C, DM and DMT (13 cm, pH 3-10, NL). Spot numbers correspond to those in Tables II and III.

protein spots were successfully identified by LTQ-ESIMS/MS, including standard spot (SSP) number on 2-DE DIGE gels, Swiss-Prot accession number, protein description, theoretical Mr/PI, unique peptides and sequence coverage (Table III). In the aorta of diabetic rats, the expression of 23 proteins was significantly changed in comparison to normal. Among them, the expression of 15 proteins was also found either down-regulated or up-regulated after treatment with GSPE, as shown in Table IV. In brief, the differentially expressed proteins were related to many important biological functions including metabolism, oxidative stress, signal transduction, cell proliferation, cell growth, apoptosis and heat shock. Among these proteins, in comparison with the aortic tissue of diabetic rats, the differential proteomic analysis of the aortic tissue of diabetic rats, treated by GSPE further revealed the variation of 15 proteins, namely, lamin A, ATP synthase $\alpha$ chain, proline arginine-rich end leucine-rich repeat protein precursor (PRELP), LOC500183 protein, HSP27, enoyl-CoA hydratase (ECH), glutamate dehydrogenase $(\mathrm{GDH})$, protein-L-isoaspartate (D-aspartate) O-methyltransferase 1 (PIMT1), lactadherin, leucine aminopeptidase 3 (LAP 3), adenylyl cyclase-associated protein 1 (CAP 1), apolipoprotein A-I (ApoA-I), catalase, Dermcidin and fibrinogen $B$ chain.

Effects of GSPE on the expression of HSP27. By quantitative real-time PCR, it was found that the expression of HSP27 mRNA of diabetic rats was significantly higher than that of control rats $(\mathrm{P}<0.01)$; the expression of HSP27 mRNA decreased after treatment with GSPE (Fig. 5). By immuno- 


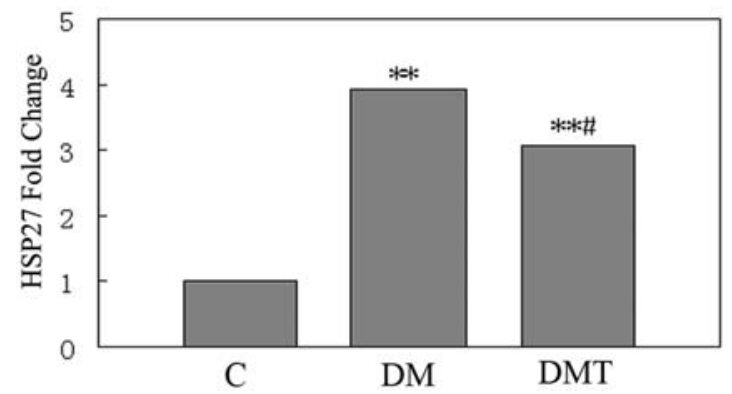

Figure 5. Effects of GSPE on the expression of HSP27 mRNA by quantitative real-time PCR. Change in gene expression is expressed as fold change in relation to controls. ${ }^{*} \mathrm{P}<0.05,{ }^{* *} \mathrm{P}<0.01$ compared with $\mathrm{C}$; ${ }^{*} \mathrm{P}<0.05,{ }^{\#} \mathrm{P}<0.01$ compared with DM. C, untreated control group; DM, untreated diabetic group; DMT, GSPE-treated diabetic group.

histochemistry, it was found that the grey value of HSP27 in diabetic rats decreased comparing to that of control rats $(\mathrm{P}<0.01)$. After treatment with GSPE, the grey value of HSP27 in group DMT increased compared to group DM (Fig. 6). By Western blot analysis, it was found that the protein expression of HSP27 in diabetic rats increased compared to that of control rats $(\mathrm{P}<0.01)$; after treatment with GSPE, the expression of HSP27 in group DMT decreased compared to group DM (Fig. 7), which was in accordance with the result of 2-D DIGE, immunohistochemistry and quantitative real-time PCR.

\section{Discussion}

Despite the advances made in therapeutic approaches to control blood glucose and insulin levels in diabetic patients, the precise and constant regulation of these levels remains problematic and leads to pathogenic consequences. Arteriosclerosis is the most prevalent of these complications. Macrovascular complications are a major cause of morbidity and mortality in patients with DM (16). The major mechanisms reported include accelerated glycation, increased protein kinase $\mathrm{C}$ activity and increased oxidative stress in the body (17). However, the molecular basis for the accelerated arteriosclerosis in DM has not been fully elucidated. Defining the pathophysiologic mechanisms of diabetic macrovascular complications are necessary to identify new targets for therapeutic intervention.

Conventionally, 2-DE has relied on Coomassie blue or silver staining combined with image analysis to visualize gel separated proteins. In this study, 2-D DIGE exhibits more accurate qualitative and quantitative analysis by running multiple sample lysates prelabeled with three matched cyanine dyes within the same gel. The use of pre-electrophoretic label with fluorescent dyes and an internal standard created by pooling aliquots of all the samples in the experiment improves the sensitivity and dynamic range of protein detection $(18,19)$.

The STZ-induced diabetic rats used in this study developed degenerative changes. These changes were similar to those seen in diabetic process. The aortic lesion in STZ-induced diabetic rats was characterized previously by showing aortic histologic changes commonly seen in human diabetic arteriosclerosis, including vascular smooth muscle cell proliferation, aortic lumens stenosis and aortic remodeling. STZ-induced diabetic rats presented many of the features observed in human diabetic arteriosclerosis. 


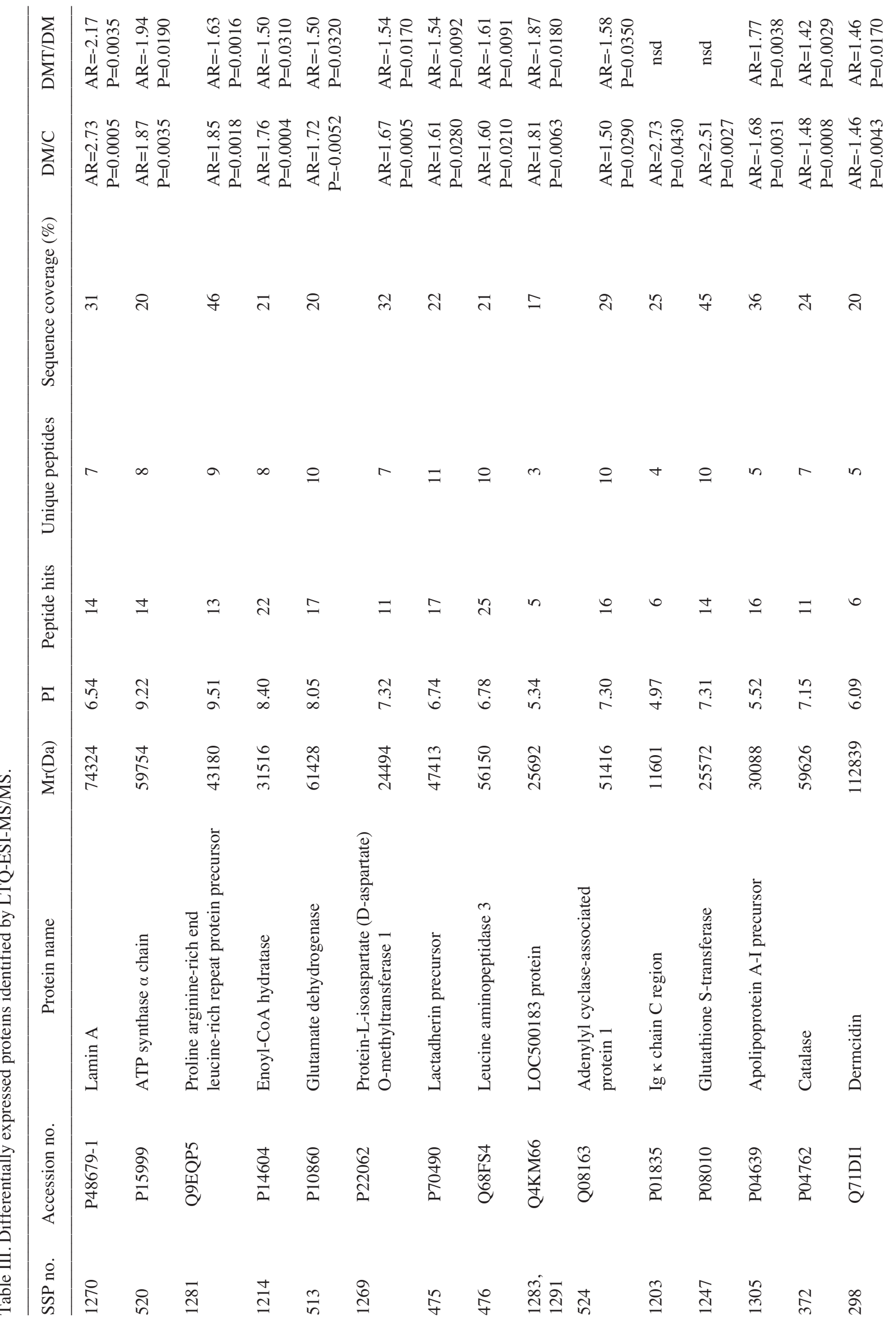




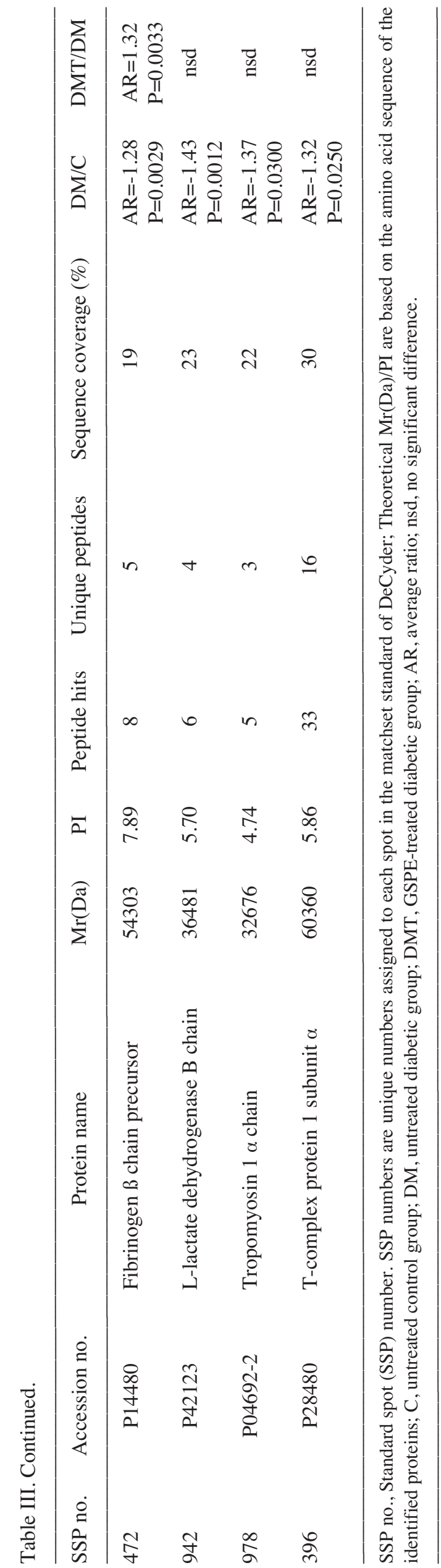

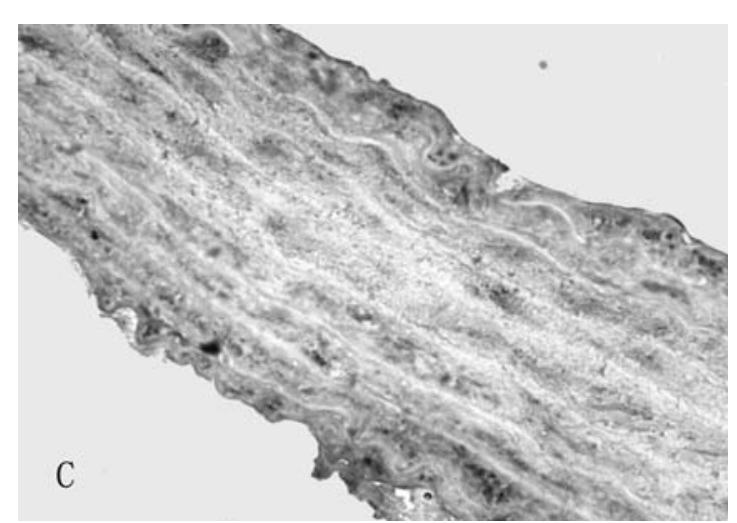
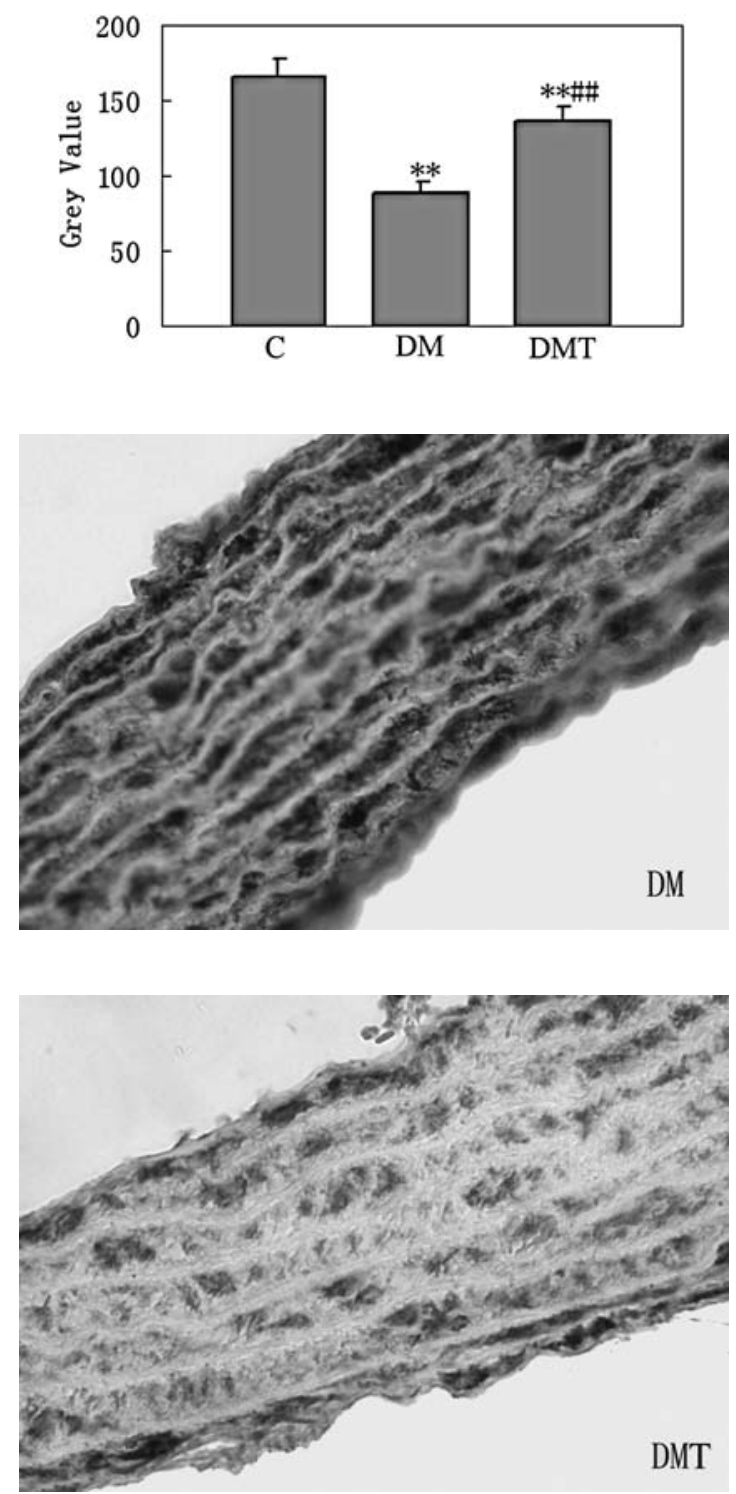

Figure 6. Effects of GSPE on the expression of HSP27 by immunohistochemistry (x400). ${ }^{*} \mathrm{P}<0.05,{ }^{* *} \mathrm{P}<0.01$ compared with $\mathrm{C} ;{ }^{~} \mathrm{P}<0.05,{ }^{* \#} \mathrm{P}<0.01$ compared with DM. C, untreated control group; DM, untreated diabetic group; DMT, GSPE-treated diabetic group.

Our results indicated that diabetic rats induced by STZ showed body weight reduction during the 24 weeks experimental period, suggesting that these animals were undergoing growth retardation due to the obstruction of glucose uptake caused by the lack of insulin following STZ injection, but 
Table IV. Summary of the 15 proteins.

\begin{tabular}{lcccc}
\hline Protein & Average ratio & Average ratio & Average ratio & \\
identification & DM1/C & DM2/DM1 & DM2/C & Function
\end{tabular}

\begin{tabular}{|c|c|c|c|c|}
\hline Lamin A & 2.73 & -2.71 & 1.02 & $\begin{array}{l}\text { A passive structural framework underlying and } \\
\text { supporting the nuclear envelope and contri- } \\
\text { buting to nuclear envelope assembly }\end{array}$ \\
\hline ATP synthase $\alpha$ chain & 1.87 & -1.94 & -1.04 & $\begin{array}{l}\text { Membrane-bound enzyme complexes/ion } \\
\text { transporters that combine ATP synthesis and/o } \\
\text { hydrolysis with the transport of protons across } \\
\text { a membrane }\end{array}$ \\
\hline
\end{tabular}

Proline arginine-rich

end leucine-rich repeat

protein precursor

LOC500183 protein

1.85

$-1.63$

1.13

1.81

$-1.87$

$-1.03$

$27 \mathrm{kDa}$ heat shock

protein

1.76

$-1.74$

Enoyl-CoA hydratase

1.76

$-1.50$

1.72

$-1.50$

dehydrogenase

Protein-L-isoaspartate

(D-aspartate)

O-methyltransferase 1

1.67

$-1.54$

1.61

$-1.54$

1.04

Lactadherin precursor

Leucine

aminopeptidase 3

1.60

$-1.61$

$-1.01$

1.50

$-1.58$

$-1.05$

associated protein 1

Apolipoprotein A-I

precursor

$-1.68$

Catalase

$-1.48$

1.77

1.05

1.42

$-1.04$

Dermcidin

$-1.46$

1.46

$-1.00$

Fibrinogen $B$ chain

precursor

$-1.28$
1.32
A member of the family of extracellular matrix small leucine-rich repeat proteins

Similar to NGF-binding Ig light chain

A molecular chaperone mediates cytoprotective effects

Which encodes enzyme involved in fatty acid ß-oxidation

A key enzyme in nitrogen metabolism

Initiate the conversion of Lisoaspartyl and Daspartyl residues to normal L-aspartyl residues

A glycoprotein be expressed by mammary epithelial cells as a cell surface protein and secreted as part of the milk fat globule membrane

Play an important role in many biological functions such as protein maturation, protein degradation, hormone level regulation, and cell cycle control

An important regulator of actin dynamics in vivo and in vitro

A primary protein constituent of HDL

Which converts hydrogen peroxide into water and oxygen gas

A novel antibiotic peptide secreted by sweat glands

Plays a central role in the mechanism of coagulation and thrombosis treatment with GSPE increased the body weight from the initial value. It had been reported GSPE have anti-oxidant properties as evidenced by the increase in pancreatic glutathione and reduction of lipid peroxidation, so it might improve the function of $\beta$ cell in the diabetic rats and influenced insulin effects by directly acting on specific components of the insulin-signaling transduction pathway $(8,20)$. On the contrary, the levels of serum glucose, $\mathrm{HbA}_{1} \mathrm{c}$ and AGEs observed in untreated diabetic rats were increased beyond those of untreated control rats. However, GSPE-treated diabetic rats showed significant 

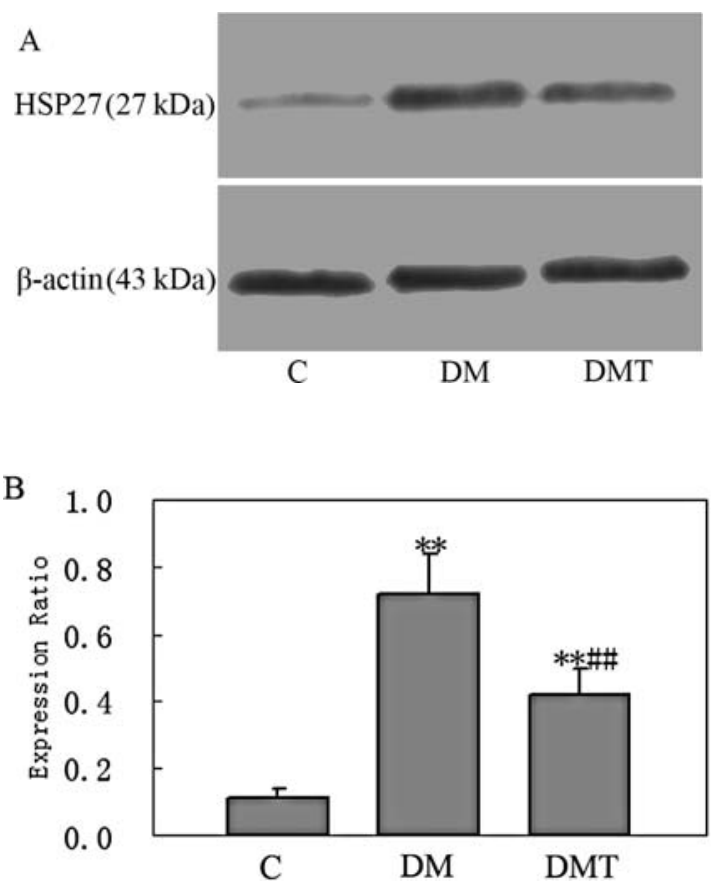

Figure 7. Effects of GSPE on the expression of HSP27 by Western blot analysis (A and B). Data are expressed as the expression ratio of HSP27/ Bactin and given as mean $\pm \mathrm{SD}$ from three experiments. ${ }^{*} \mathrm{P}<0.05,{ }^{* *} \mathrm{P}<0.01$

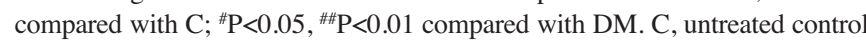
group; DM, untreated diabetic group; DMT, GSPE-treated diabetic group.

reductions in AGEs levels compared with untreated diabetic rats. Therefore, we supposed that GSPE could have an antinon-enzymatic glycation effect, having a correlation with body weight gain. By histological study, it was found that GSPE had protective effects on the aorta of diabetic rats. Moreover, activity of isolated procyanidins from grape seed tended to increase with degree of polymerization, epicatechin content and with galloylation. GSPE was useful in preventing or treating cardiovascular diseases (21).

2-DE DIGE and MS were used to investigate aorta protein profiles among C, DM and DMT. The results showed that many proteins changed in diabetic rats, wherein 15 changed proteins were restored after GSPE therapy. Lamin A was found up-regulated in the aorta of diabetic rats and down-regulated in the aorta of GSPE-treated diabetic rats. Lamin A was an adhesion-related molecule. Adhesion molecules were analyzed in aortic lesions, which enhanced the intercellular adhesion of arteries in arteriosclerosis. The major receptors of lamin A were shown to be integrins and dystroglycan, which were also important in the inflammatory reactions during the development of diabetic arteriosclerosis (22). The results suggested that the inhibition effect of GSPE on lamin A at least partly contributed to the improvement of diabetic arteriosclerosis.

HSP27 was a member of the stress-inducible small heat shock protein family that was thought to have multiple functions in cellular processes (including stress tolerance, apoptosis and modulation of actin filament dynamics). The expression of HSP27 of diabetic rats was significantly higher than those of control rats by quantitative real-time PCR, immunohistochemistry, Western blot analysis and 2D DIGE.
After treatment with GSPE, the expression of HSP27 in group DMT decreased compared to group DM. There were data indicating that the phosphorylation of HSP27 could modulate the polymerization of actin and cytoskeleton remodeling, which were thought to be a key step in cell migration (23). It was reported that platelet-derived growth factor activated migration was significantly inhibited in the transfected rat aortic smooth muscle cells with siRNA-HSP27 (24). Therefore, we need do further research on the function of HSP27 in the aortic remodeling of DM.

Moreover, ApoA-I and catalase were found downregulated in the aorta of diabetic rats and up-regulated in the aorta of GSPE-treated diabetic rats. ApoA-I, a major protein constituent of native high density lipoprotein (HDL) because of its role in reverse cholesterol transport, had been implicated in the prevention of arteriosclerosis. Previous studies showed that ApoA-I protected not only from arteriosclerosis but also from diabetes mellitus and inflammation-induced organ damage (25). It was reported that there was a possible link between HDL and ApoA-I metabolism and arteriosclerosis in patients with type 2 diabetes (26). Catalase is one of the endogenous anti-oxidant enzymes and could convert hydrogen peroxide into water and oxygen gas. Previous study also revealed that GSPE inhibited ultraviolet radiation induced depletion of catalase in normal human epidermal keratinocytes and restored the activity of catalase (27). In our study, it was shown that GSPE increased the expression of catalase in diabetic rats. It suggested that the activation effect of GSPE on ApoA-I and catalase at least partly contributed to reducing the aortic lesions in DM.

These findings strongly supported that those up-regulated or down-regulated proteins might play a key role in the development and recovery of diabetic macrovascular complications. Reversible proteins were mostly relevant to oxidative stress, cell proliferation and apoptosis, inflammatory pathways and substance metabolism. It indicated that GSPE therapy caused high aortic remodeling recovery mainly by regulating the above processes. Those involved proteins might form the basis of functional regulation. Meanwhile, some changed proteins in diabetic rats did not back-regulate after GSPE therapy. So whether those proteins were contributing factors in diabetic macrovascular complications in pathogenesis demands further research. We explored the proteomic changes after natural medicine therapy for the very first time and revealed that the expression of some proteins were upregulated or down-regulated after GSPE therapy. These proteins are most likely to participate in the deterioration and restoration as important functional proteins and to provide target candidates for treatment.

\section{Acknowledgements}

This study was supported by National Natural Science Foundation of China (30873145). We wish to thank the personnel in Research Center for Proteome Analysis, Shanghai Institute for Biological Sciences, Chinese Academy of Sciences and the Center for New Drug Evaluation of Shandong University. We also thank Professor Rui-hai Zhou and Cheng-mei Zhang for their assistance. 


\section{References}

1. Henry RM, Kostense PJ, Spijkerman AM, Dekker JM, Nijpels G, Heine RJ, Kamp O, Westerhof N, Bouter LM and Stehouwer CD: Arterial stiffness increases with deteriorating glucose tolerance status: the Hoorn Study. Circulation 107: 2089-2095, 2003.

2. Terry JG, Tang R, Espeland MA, Davis DH, Vieira JL, Mercuri MF and Crouse JR: Carotid structure in patients with documented coronary artery disease and disease-free control subjects. Circulation 107: 1146-1151, 2003.

3. Houde V, Grenier D and Chandad F: Protective effects of grape seed proanthocyanidins against oxidative stress induced by lipopolysaccharides of periodontopathogens. J Periodontol 77: 1371-1379, 2006.

4. Zi SX, Ma HJ, Li Y, Liu W, Yang QQ, Zhao G and Lian S: Oligomeric proanthocyanidins from grape seeds effectively inhibit ultraviolet-induced melanogenesis of human melanocytes in vitro. Int J Mol Med 23: 197-204, 2009.

5. Yamakoshi J, Kataoka S, Koga T and Ariga T: Proanthocyanidinrich extract from grape seeds attenuates the development of aortic arteriosclerosis in cholesterol-fed rabbits. Arteriosclerosis 142: 139-149, 1999

6. Zhang FL, Gao HQ, Wu JM, Ma YB, You BA, Li BY and Xuan JH: Selective inhibition by grape seed proanthocyanidin extracts of cell adhesion molecule expression induced by advanced glycation end products in endothelial cells. J Cardiovasc Pharmacol 48: 47-53, 2006.

7. Ma L, Gao HQ, Li BY, Ma YB, You BA and Zhang FL: Grape seed proanthocyanidin extracts inhibit vascular cell adhesion molecule expression induced by advanced glycation end products through activation of peroxisome proliferators-activated receptor gamma. J Cardiovasc Pharmacol 49: 293-298, 2007.

8. Pinent M, Blay M, Bladé MC, Salvadó MJ, Arola L and Ardévol A: Grape seed-derived procyanidins have an antihyperglycemic effect in streptozotocin-induced diabetic rats and insulinomimetic activity in insulin-sensitive cell lines. Endocrinology 145: 4985-4990, 2004.

9. Holm AM, Andersen CB, Hauns $\varnothing$ S and Hansen PR: ACEinhibition promotes apoptosis after balloon injury of rat carotid arteries. Cardiovasc Res 45: 777-782, 2000.

10. Buus CL, Pourageaud F, Fazzi GE, Janssen G, Mulvany MJ and De Mey JG: Smooth muscle cell changes during flow-related remodeling of rat mesenteric resistance arteries. Circ Res 89: 180-186, 2001.

11. Li BY, Cheng M, Gao HQ, Ma YB, Xu L, Li XH, Li XL and You BA: Back-regulation of six oxidative stress proteins with grape seed proanthocyanidin extracts in rat diabetic nephropathy. J Cell Biochem 104: 668-679, 2008.

12. Ji H, Moritz RL, Kim YS, Zhu HJ and Simpson RJ: Analysis of Ras-induced oncogenic transformation of NIH-3T3 cells using differential-display 2-DE proteomics. Electrophoresis 28 1997-2008, 2007.

13. Cimmino F, Spano D, Capasso M, Zambrano N, Russo R, Zollo $\mathrm{M}$ and Iolascon A: Comparative proteomic expression profile in all-trans retinoic acid differentiated neuroblastoma cell line. J Proteome Res 6: 2550-2564, 2007.
14. Ritorto MS and Borlak J: A simple and reliable protocol for mouse serum proteome profiling studies by use of twodimensional electrophoresis and MALDI TOF/TOF mass spectrometry. Proteome Sci 6: 25, 2008.

15. D'Hertog W, Overbergh L, Lage K, Ferreira GB, Maris M, Gysemans C, Flamez D, Cardozo AK, Van den Bergh G, Schoofs L, Arckens L, Moreau Y, Hansen DA, Eizirik DL, Waelkens E and Mathieu C: Proteomics analysis of cytokineinduced dysfunction and death in insulin-producing INS-1E cells: new insights into the pathways involved. Mol Cell Proteomics 6: 2180-2199, 2007.

16. Stenina OI, Krukovets I, Wang K, Zhou Z, Forudi F, Penn MS, Topol EJ and Plow EF: Increased expression of thrombospondin-1 in vessel wall of diabetic Zucker rat. Circulation 107: 3209-3215, 2003.

17. Brownlee M: Biochemistry and molecular cell biology of diabetic complications. Nature 414: 813-820, 2001.

18. Prabakaran S, Wengenroth M, Lockstone HE, Lilley K, Leweke FM and Bahn S: 2-D DIGE analysis of liver and red blood cells provides further evidence for oxidative stress in schizophrenia. J Proteome Res 6: 141-149, 2007.

19. Shiota M, Kusakabe H, Hikita Y, Nakao T, Izumi Y and Iwao H: Pharmacogenomics of cardiovascular pharmacology: molecular network analysis in pleiotropic effects of statin-an experimental elucidation of the pharmacologic action from protein-protein interaction analysis. J Pharmacol Sci 107: 15-19, 2008.

20. El-Alfy AT, Ahmed AA and Fatani AJ: Protective effect of red grape seeds proanthocyanidins against induction of diabetes by alloxan in rats. Pharmacol Res 52: 264-270, 2005.

21. Fitzpatrick DF, Bing B, Maggi DA, Fleming RC and O'Malley RM: Vasodilating procyanidins derived from grape seeds. Ann NY Acad Sci 957: 78-89, 2002.

22. Almofti MR, Huang Z, Yang P, Rui Y and Yang P: Proteomic analysis of rat aorta during arteriosclerosis induced by high cholesterol diet and injection of vitamin D3. Clin Exp Pharmacol Physiol 33: 305-309, 2006

23. Huot J, Houle F, Marceau F and Landry J: Oxidative stressinduced actin reorganization mediated by the p38 mitogenactivated protein kinase/heat shock protein 27 pathway in vascular endothelial cells. Circ Res 80: 383-392, 1997.

24. Lee CK, Lee HM, Kim HJ, Park HJ, Won KJ, Roh HY, Choi WS, Jeon BH, Park TK and Kim B: Syk contributes to PDGF-BBmediated migration of rat aortic smooth muscle cells via MAPK pathways. Cardiovasc Res 74: 159-168, 2007.

25. Rohrer L, Hersberger M and von Eckardstein A: High density lipoproteins in the intersection of diabetes mellitus, inflammation and cardiovascular disease. Curr Opin Lipidol 15: 269-278, 2004.

26. Han R, Lai R, Ding Q, Wang Z, Luo X, Zhang Y, Cui G, He J, Liu W and Chen Y: Apolipoprotein A-I stimulates AMP-activated protein kinase and improves glucose metabolism. Diabetologia 50: 1960-1968, 2007.

27. Mantena SK and Katiyar SK: Grape seed proanthocyanidins inhibit UV-radiation induced oxidative stress and activation of MAPK and NF-kappaB signaling in human epidermal keratinocytes. Free Radic Biol Med 40: 1603-1614, 2006. 